Pascale Braconnot ${ }^{1}$, S.P. Harrison ${ }^{2}$, S. Tudhope $^{3}$ and C. Michaut ${ }^{4}$

'Laboratoire des Sciences du Climat et de l'environnement, CEA-CNRS, Gif-Sur-Yvette, France; pascale.braconnot@lsce.ipsl.fr ${ }^{2}$ School of Biological Sciences, Macquarie University, North Ryde, Australia; ${ }^{3}$ Departement of Geology and Geophysics, University of Edinburgh, UK: ${ }^{4}$ Institut Pierre Simon Laplace, UVSQ, France

T wenty scientists assembled at Villefranche-sur-Mer, southern France to foster analyses of past climate variability from model and observations. They included scientists representing a diversity of high-resolution climate archives and climate modelers focusing on the analysis of short-term variability in paleoclimate simulations. The Observatory of Haute Provence served as the workshop venue thanks to support from the staff of that institute. The charming location, perfect Mediterranean weather, excellent food, and enthusiasm of the participants all contributed to make this a stimulating and productive workshop. WCRP, PAGES, INQUA/PALCOMM and IPSL supported this meeting.

The El-Niño/Southern Oscillation (ENSO) is the major mode of climate variability in tropical regions. ENSO monitoring, understanding, and prediction have received a lot of attention in recent decades because it strongly affects the economy of tropical regions and beyond (McPhaden et al. 2006). However, there remain major uncertainties regarding the fluctuations and future evolution of ENSO. The increasing number of records from natural archives (corals, mollusk shells, varved sediments, speleothems, tree rings, etc.) with annual or sub-annual resolution now available finally enables us to draw a consistent picture of past changes in tropical climate variability. On the modeling side, the Last Millennium, the MidHolocene ( $6 \mathrm{ka}$ ) and the Last Glacial Maximum (21 ka) are the three main foci of the CMIP5/PMIP3 project for multi-model ensemble paleoclimate simulations (Taylor et al. 2011). These paleo-simulations are run with the same model version that each modeling group is using for future climate projections in CMIP5. This allows us to test how the simulated variability is affected by changes in the climate background state. However, to evaluate how well these models reproduce observed changes in ENSO variability, it is first necessary to produce a pan-tropical synthesis of past changes in ENSO variability that

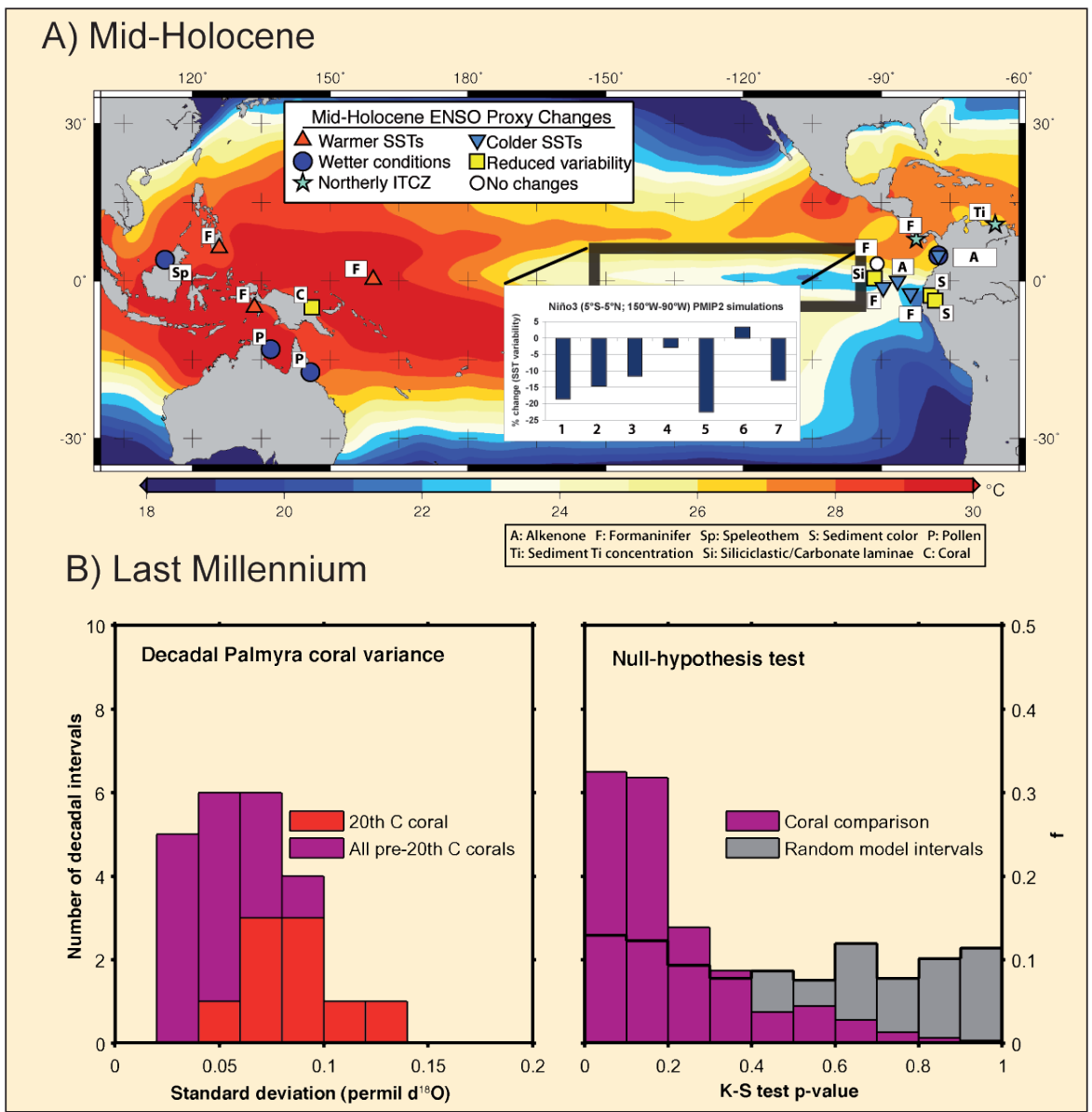

Figure 1: Analyses of ENSO and model-data comparison for the mid-Holocene and the Last Millennium. A) Map showing a synthesis of the Pacific state during the mid-Holocene (from Braconnot et al. 2011), together with the change in EI-Niño variability (\%) as simulated by PMIP2 simulations \# 1-7 (inset, Zheng et al. 2008). Coral data (Tudhope et al. 2001, " $C$ ") indicate a $60 \%$ reduction in ENSO, suggesting that simulations underestimate the observed changes (Brown et al. 2008). The background shows SSTs during the La Niña event of December 1998. The results in (B) are from Russon et al. (unpublished data). Left panel: Distribution of decadal standard deviations of stable oxygen isotope records from modern and fossil corals (Cobb et al. 2003). Variance was relatively lower before than during the $20^{\text {th }}$ century. Right panel: Kolmogorov-Smirnov test of the null hypothesis that the two probability density functions shown in the left panel are drawn from the same distribution. For the coral comparison (purple bars) $p$-values are generally $<0.2$, suggesting rejection of the null hypothesis, whereas an equivalent comparison of randomly sampled control run data of the HadCM3 climate model (gray bars) is consistent with the null hypothesis. Thus, the differences between the decadal variance properties of ENSO in the $20^{\text {th }}$ Century and the pre-20 $0^{\text {th }}$ Century are likely to represent forced ENSO variability.

includes all the possible types of record and a critical evaluation of these records. Furthermore, specific criteria and new methodologies need to be developed to facilitate data-data and data-model comparisons.

In this context, the objectives of this meeting were to determine the best way to produce a "synthetic" product on shortterm (interannual to decadal) climate variability in tropical regions and to design analyses of the CMIP5/PMIP3 simulations.
On the first day, participants presented the modeling tools, summarized available paleodata and discussed the difficulties inherent in the analysis and interpretation of these records including how to overcome them. Thereafter, two working groups (focusing on the Last Millennium and the mid-Holocene) discussed interpretative issues and determined the best way to include information from different archives within a common framework. The working groups also discussed the 
analyses of model experiments and observations to characterize variability for each time period. Several plenary sessions allowed discussion of cross-cutting methodological issues.

A plan for a multi-authored publication in a high-profile journal of the current state-of-knowledge about changes in tropical variability based on data analysis, model experiments and data-model comparisons emerged from the working group efforts. The meeting participants produced a draft outline for this paper, including key results and design of the figures.

These three intensive days of meeting are only the beginning. Work will continue in the coming months with the aim of completing the synthesis paper early next year. In addition, several participants agreed to contribute to a PAGES (or PAGES/CLIVAR Intersection) newsletter focused on past ENSO.

\section{Selected references}

Full reference list online under:

http://www.pages-igbp.org/products/newsletters/ref2012_1.pdf

Braconnot P, Luan Y, Brewer S and Zheng W (2011) Climate Dynamics, doi: $10.1007 / 500382-011-1029-x$

Brown J, Tudhope AW, Collins M and MCGregor HV (2008) Paleoceanography 23(3), doi: 10.1029/2007pa001512

Cobb KM, Charles CD, Cheng H and Edwards RL (2003) Nature 424: 271-276

Tudhope AW et al. (2001) Science 291: 1511-1517

Zheng W et al. (2008) Climate Dynamics 30: 745-762

\title{
North American Dendroclimatic
}

\section{Data: Compilation, Characterization, and Spatiotemporal Analysis}

\author{
NAM2k Workshop, Tucson, USA, 26-28 October 2011
}

\author{
Valerie Trouet ${ }^{1}$, D. Stahle ${ }^{2}$ and H. Diaz ${ }^{3}$ \\ 'Laboratory for Tree-Ring Research, University of Arizona, Tucson, USA; trouet@ltrr.arizona.edu \\ ${ }^{2}$ Department of Geosciences, University of Arkansas, Fayetteville, USA; ${ }^{3}$ Cooperative Institute for Research in Environmental Sciences, University \\ of Colorado, Boulder, USA
}

\section{D} uring the first meeting of the PAGES North American 2k Working Group (NAM2k) in Flagstaff, USA, in May 2011, a task group was assigned to collaborate on the assimilation of available data sources and exploration of spatiotemporal analysis tools. Considering the numerical dominance of tree-ring data within the climate proxy data pool for North America, this task group focuses in first instance on compiling and analyzing tree-ring data, with the goal of producing a high-resolution reconstruction of key climate variables for North America (including Canada, USA, and Mexico). The necessary steps towards achieving this goal were discussed by 12 paleoclimatologists from the USA and Canada in a workshop held at the University of Arizona in Tucson. The workshop was supported by the University's Institute of the Environment and by PAGES.

The participants first discussed available tree-ring data and their characteristics, including time-series length, seasonality, climate parameter calibration, and geographic representation (Fig. 1). The North American Drought Atlas (NADA, Cook et al. 2004) was generally accepted as a spatially explicit, high-resolution drought reconstruction for North America that can likely not be improved upon without extensive new data collection. The working group will therefore aim to complement the NADA with a continentalscale temperature reconstruction equivalent.

Two general approaches to the development of such a gridded temperature reconstruction were suggested: (1) compilation of all available tree-ring data, regardless of the strength of their temperature-sensitivity and extraction of the best possible temperature signal out of this extended data set or (2) a priori selection of best qualified tree-ring data and reconstruction development based on this limited data-set. The workshop participants decided to adopt the second approach

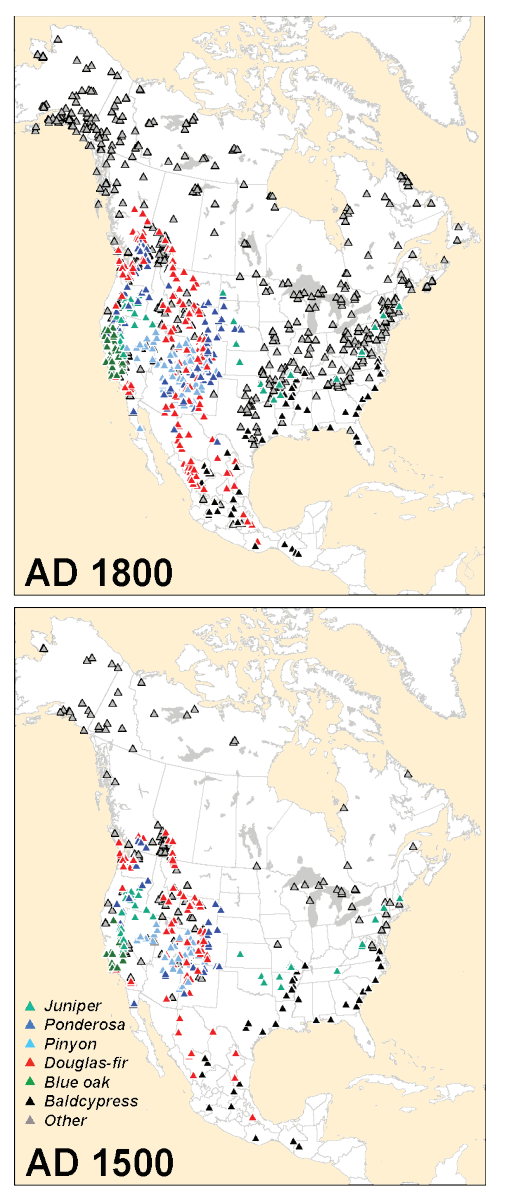

Figure 1: Species-specific tree-ring chronologies available for the North American continent that extend back to $A D 1800$ and $A D 1500$. and defined a set of selection criteria including a minimum time-span covered by the tree-ring series (AD 1650-1990) and strength $(r>0.316)$, sign (positive), and seasonality (summer) of the temperature signal in the tree-ring series. Tree-ring chronologies from the International Tree-Ring Database (ITRDB) will be screened according to these criteria and complemented by chronologies from individual researchers, which have not yet been contributed to the ITRDB. The raw ring-width data contributing to the selected chronologies will be detrended using a signal-free approach before implementation in the reconstruction algorithm.

The task group aims to first apply a nested empirical orthogonal functions (EOF) based methodology. In a first step, only the tree-ring data covering the time-period $A D$ 1200-1990 will be included. The next phase will include all previously selected tree-ring data. In addition to this EOF-based approach for spatial reconstruction, a Bayesian Hierarchical Model (BHM) will be used to extract climate information from the tree-ring time-series. Both methodologies will initially be run on annual time-scales, but also decadal-scale reconstructions will be developed that allow for inclusion of other, decadal-resolution proxies, including pollen data. For this purpose, the NAM2K working group will collaborate closely with the Arctic working group and a joint workshop will be organized.

\section{Reference}

Cook ER et al. (2004) Science 306(5698): 1015-1018 